\title{
Promoting adoption while avoiding rebound: integrating disciplinary perspectives on market diffusion and carbon impacts of electric cars and building renovations in Austria
}

\author{
Sebastian Seebauer ${ }^{*}$, Veronika Kulmer and Claudia Fruhmann
}

\begin{abstract}
Background: Many countries state ambitious targets for reducing carbon emissions. Their policy strategies emphasize energy efficiency by means of technological innovations. However, these strategies are at risk of severe rebound effects, as savings from more efficient products and facilities may be (over-)compensated by rearrangements in consumer behavior. While rebound effects are widely acknowledged, it is less clear how they arise from the complex interactions between market actors, consumer preferences, and policy initiatives.

Results: We propose a simplified representation of these complex dynamics, in order to point out levers for counteracting rebound effects. A pathway mapping integrates results from fuzzy cognitive mapping of expert knowledge, from a household survey on adoption and use and from macroeconomic modelling of energy efficiency policies. Core drivers identified across all methods are joined to a cause-and-effect diagram. The respective strengths of influence are standardized to effect coefficients. By tracing policy impulses through the web of interlinked drivers, the pathway mapping illustrates direct, mediated, and unintended impacts on market diffusion, rebound, and carbon emission reductions of energy-efficient technologies. Pathway mapping is demonstrated as an approach for integrating diverse disciplinary methods into a joint narrative illustrating overarching dynamics.

Conclusions: Applying this methodology to building renovations and electric cars in Austria, the need to balance technology adoption and use becomes apparent. Convergent drivers stimulate the market uptake of the energy-efficient technology and simultaneously constrain rebound effects. For instance, educating customers on product features and activating their pro-environmental values, encourages technology adoption as well as ecological use. Contrastingly, divergent drivers have opposing effects on adoption and use. For example, fuel taxes counteract rebound, but also hinder adoption by increasing lifetime costs. Higher income enables adopters to carry upfront investment costs, but also increases spending in other, carbon-intensive consumption domains. The pathway maps show that market-oriented instruments promote the adoption of energy-efficient technologies but also the rebound effect in their subsequent use. Policy interventions should be carefully designed to leverage convergent and to circumnavigate divergent drivers in order to address multiple impact paths. Climate strategies should not underestimate the role of socio-psychological characteristics and key actors.
\end{abstract}

Keywords: Rebound effect, Technological innovation, System analysis, System model, Energy efficiency, Policy design

\footnotetext{
* Correspondence: sebastian.seebauer@joanneum.at

LIFE - Centre for Climate, Energy and Society, JOANNEUM RESEARCH

Forschungsgesellschaft mbH, Waagner-Biro-Straße 100, 8020 Graz, Austria
}

(c) The Author(s). 2019 Open Access This article is distributed under the terms of the Creative Commons Attribution 4.0 International License (http://creativecommons.org/licenses/by/4.0/), which permits unrestricted use, distribution, and reproduction in any medium, provided you give appropriate credit to the original author(s) and the source, provide a link to the Creative Commons license, and indicate if changes were made. 


\section{Background}

In order to achieve the ambitious climate targets set by the COP21 climate conference in Paris in 2015, many countries promote innovative, energy-efficient technologies $[1,2]$. The broad market launch of electric cars or the refurbishment of existing buildings through thermal insulation are intended to reduce energy demand and greenhouse gas emissions [3]. This strategy of advancing energy-efficient technologies is successful if, on the one hand, these technologies quickly penetrate the mass market (i.e., adoption) and, on the other hand, the gain in technical efficiency is not compensated for by a change in use (i.e., rebound effect). The present article argues that these two processes, adoption and use, are affected by the same factors. Climate policy instruments aimed at increasing adoption rates often lay the groundwork for a later rebound effect. For example, the parking benefits given to e-cars in many cities may make the purchase of an e-car more attractive [4]. However, the good parking space availability may entice users to use the e-car on trips where they previously took the bicycle or public transport. Building renovation is promoted with the prospect of lower heating costs [5]. The more this motivation stands in the foreground, the more strongly the residents are encouraged to treat themselves to a more comfortable room temperature with the cheaper heating system [6, 7].

Adoption and use are linked by the costs an energyefficient technology incurs for the individual consumer. At the time of the purchase decision for an energy-efficient technology, one already anticipates how soon the investment costs will be amortized and how high the operational costs will be [8]. Since the efficient technology provides the energy service with less energy consumption and therefore lower costs, the frequency and intensity of use increases (direct rebound effect $[9,10]$ ). In addition, cost savings increase the disposable income that can be spent on other energy-consuming goods and services (indirect rebound effect $[11,12])$. These supply and demand adjustment processes add up across all economic sectors (economy-wide rebound effect [13-15]). Rebound effects at the level of private consumers are not only caused by monetary incentives, but also by motivational processes: with the adoption of an efficient technology, one has the feeling of having already made an ecological contribution. Now one can indulge oneself in other consumption domains without a guilty conscience [16].

The observation that realized emission savings from energy-efficient technologies often fall short of initial expectations is increasingly being taken up in the political discussion [7]. Direct rebound effects in housing and transport are estimated at $10-30 \%$ of the expected savings [9]. Estimates of indirect and economy-wide rebound effects range from 20 to $300 \%$ [13, 17, 18]. Given this level of rebound effects, there is an urgent need to develop policy options for rebound prevention.

Both adoption and (changed) use take place within the same socio-technical regime, in interaction with the same market actors and influenced by the same consumer attributes $[19,20]$. Not just acquisition and operating costs, but also existing infrastructure and competing products on the market are relevant both for the purchase decision and for ongoing use [21]. Subsidies and regulations as well as communication in the mass media also play a double role [22]. Both the buying decision and everyday use depend on income, environmental values, and the level of consumer knowledge [23, 24]. A policy instrument that targets infrastructure, for example, or provides incentives for individual market players such as retailers and tradespeople, will therefore influence both adoption and rebound. Thus, integrative policy design requires analytical tools capable of capturing the full range of consumer decisions.

So far, factors influencing rebound have mainly been investigated from the perspectives of separate research fields (e.g., ecological economics [15], building engineering [25], environmental psychology [23]). Investigating complex problems however often requires a broader, multifaceted perspective; consequently, growing interest is given to the question of integrating qualitative and quantitative methods within a single research design [26-28]. For instance, mixed-method approaches in environmental policy research seek to improve the validity and robustness of findings and derived policy recommendations [29-32]. How different methods are combined best remains contested though, ranging from triangulation (comparison of method-specific findings), sequential design (one method narrows the research focus for the ensuing methods, or one method explores the findings of preceding methods in more detail) to embedded design (consolidation to a common data level and scale $[32,33]$ ).

Integrating multidisciplinary approaches is often difficult because each approach highlights only parts of the overall problem and uses different methods and units of measurement [34]. In most cases, strict numerical parameterization means limiting an integrative model to economic, engineering, and natural sciences aspects. However, insights from transformation research, technology acceptance studies, and environmental psychology also play a critical role towards reaching energy and climate targets [22]. Therefore, the aim of this paper is to introduce an integrative pathway mapping that compactly illustrates how a range of "soft" and "hard" factors influence adoption as well as use of energy-efficient technologies. Next, the "Method" section describes the step-wise approach for joining three different disciplinary methods. The "Results" section shows that by tracing sequences of cause and effect within the pathway map, it becomes apparent how a political intervention may trigger unintentional or counterproductive effects. We 
conclude with policy recommendations and an outlook how to expand the pathway mapping methodology to other policy instruments and technologies. Pathway mapping, as presented here, is necessarily a simplification compared to focused, disciplinary approaches, but may illustrate overarching dynamics within a joint narrative.

\section{Method}

The integrative pathway mapping combines findings from three complementary research methods, each highlighting specific elements from the conflict between adoption and use: (i) The semi-quantitative approach of fuzzy cognitive mapping translates expert knowledge on complex real-world systems into simple cause-effect diagrams [35]. Fuzzy cognitive mapping is proven to be useful in environmental sciences for supporting policy design [36-39]. Fuzzy cognitive maps consist of nodes, i.e., relevant elements, connected by directional arrows each assigned a fuzzy quantitative weight representing the strength of its influence [40,41]. We draw on a fuzzy cognitive map derived from 12 expert interviews which identified the basic factors and actors in electric mobility and residential heating demand and weighted their causal connections [42]. (ii) Structural equation modeling is a method from multivariate statistics to empirically estimate a causal network of motivational factors jointly contributing to a specific consumer behavior [43]. The factors and their network interrelations are posited from theories of pro-environmental action or technology acceptance $[44,45]$, statistically tested for model fit and estimated for the strengths of their influences on each other. We use survey data of 575 e-car owners and 1455 persons who have carried out a building renovation to obtain regression coefficients on the impact of environmental values, social norms, and other psychological factors on rebound behavior [46]. (iii) Computable general equilibrium (CGE) models capture how a targeted economic impulse spreads across economic sectors and leads to endogenous price, income, and factor supply effects $[13,47,48]$. A CGE model calibrated to the Austrian economy estimates how a $10 \%$ energy-efficient improvement of household energy consumption in the transport and building sector leads to percentage changes in fossil fuel price, fossil fuel demand, gross domestic product (GDP), etc., or direct, indirect, and economy-wide rebound if the actual change emerges weaker than the initial 10\% impulse [49]. For space reasons, this article focuses on the overall dynamics between adoption and use and the common influencing factors. Details on the research methods can be found $[42,46,49]$. The analyses refer to the case studies of ecars and building renovations in Austria; both are largepurchase consumer technologies and typical examples in the rebound literature.
Using fuzzy cognitive mapping as a starting point, the integrative pathway mapping is developed and applied in five steps. The resulting pathway map is comparable to a bare bone system model [50]. Although presented as a linear sequence here, in practice, the map is developed iteratively, especially recurring between the consolidation, scaling, and integration steps [34]:

1. Identification,

2. Consolidation,

3. Scaling,

4. Integration, and

5. Policy analysis, supported by sensitivity analysis.

Identification determines the critical elements from each of the three research methods which have a significant influence on the adoption and use of efficiency technologies. For clarity, elements with weak or partial influence are omitted, such as causal connections assessed as negligible by experts, and regression coefficients of $p>$ .05 statistical significance level; household consumption of non-energy goods is related only to income and otherwise is covered by the indirect rebound channel in the underlying CGE model. Each method approach describes the relationships between critical elements regarding their causal direction and strength of influence.

Consolidation integrates these elements and their relationships into a common pathway map. Elements that are covered by more than one method are combined by agreeing on a joint definition. Here, the unique advantage of pathway mapping comes into play that almost everything can be described as a map element-actors, personal attributes, technical, or infrastructural aspects. The consolidated elements (see Table 1) form the building blocks of the pathway map.

In scaling, the different quantitative effects are reconciled. All method-specific effect coefficients are transformed to a common scale from 0 "no change" to 1 "multiple change" (see Table 2 for verbal anchors of numerical values). Effect coefficients are calibrated by discussing the findings of the three methods among the three authors and by agreeing to a joint value. Discussion is an established approach to achieve inter-subjectivity and to increase inter-rater reliability in qualitative social research [51]. Discussion amounts to exchanging the theoretical basis and empirical evidence from each method, taking into the account the level of confidence of the respective results, clarifying contradictions and ambiguities, and finally resolving a joint value that reflects those considerations (similar to the iterative-inductive process in grounded theory [52], or the extensive production process of IPCC reports [53]). The effect coefficients obtained through discussion are understood as semi-quantitative, fuzzy values; they act as signposts for ranking the strengths 
Table 1 List of elements per pathway map

\begin{tabular}{|c|c|}
\hline Element & Definition \\
\hline \multicolumn{2}{|l|}{ Elements included in both case studies } \\
\hline Purchase/investment & $\begin{array}{l}\text { E-car: number of e-car purchases; share of e-cars in national car stock } \\
\text { Renovations: number of renovations; number of applications for subsidies }\end{array}$ \\
\hline Direct rebound & $\begin{array}{l}\text { After adoption of the energy-efficient technology, demand for the respective } \\
\text { energy services increases }\end{array}$ \\
\hline Indirect rebound & $\begin{array}{l}\text { Due to freed-up income or moral licensing, demand for other energy-intensive } \\
\text { services and goods increases }\end{array}$ \\
\hline Economy-wide rebound & Production and demand shift to more energy- and carbon-intensive sectors \\
\hline Acquisition costs/expenditure & $\begin{array}{l}\text { E-car: acquisition costs } \\
\text { Renovations: Expenditure, depending on the intensity and quality of renovation }\end{array}$ \\
\hline GDP & Gross value added of the economy including taxes and/or subsidies on goods \\
\hline Savings in carbon emissions & Reductions in national greenhouse gas emissions across all sectors of the economy \\
\hline Mass media & $\begin{array}{l}\text { Communication of product information, including carbon footprint, sustainability, } \\
\text { and consumer benefits of various energy-efficient technologies }\end{array}$ \\
\hline Social norms & $\begin{array}{l}\text { Expectations of the social network as to whether one should acquire an energy- } \\
\text { efficient technology }\end{array}$ \\
\hline Environmental values & Personal conviction that one should engage in protecting the environment \\
\hline Variable costs & $\begin{array}{l}\text { E-car: costs per km, both monetary and convenience/time costs } \\
\text { Renovations: Costs per comfortably heated } \mathrm{m}^{2} \text { of living space after completing } \\
\text { the renovation }\end{array}$ \\
\hline Disposable income & $\begin{array}{l}\text { Household budget available; possibilities for consumption are exhausted up to } \\
\text { the personal savings rate }\end{array}$ \\
\hline Product knowledge & $\begin{array}{l}\text { E-car: knowledge about range, information from manufacturer's certificate, } \\
\text { carbon emissions per km, etc. } \\
\text { Renovations: Knowledge of renovation options, insulation materials, technologies, etc. }\end{array}$ \\
\hline Welfare & $\begin{array}{l}\text { Benefits to all households in the economy, measured as the amount of possibilities } \\
\text { for consumption limited by disposable income }\end{array}$ \\
\hline \multicolumn{2}{|l|}{ Additional elements in the e-car case study } \\
\hline Quality of alternative transport modes & Timetables and coverage of public transport, bicycle path network \\
\hline Car dealers & $\begin{array}{l}\text { Communication of product information, costs, fuel consumption, etc.; car dealers are } \\
\text { a trusted and credible source of information }\end{array}$ \\
\hline Charging infrastructure & $\begin{array}{l}\text { Public access to charging stations, the possibility to charge the e-car at home, at work } \\
\text { or during leisure activities, availability of fast charging stations, etc. }\end{array}$ \\
\hline E-car product range & A wide range of different e-car models/e-car classes \\
\hline Showcase projects & $\begin{array}{l}\text { E-mobility model regions or e-car sharing pilots as a communication channel for the } \\
\text { dissemination of product information, and as platforms for testing e-cars }\end{array}$ \\
\hline \multicolumn{2}{|c|}{ Additional elements in the building renovation case study } \\
\hline Defect-free implementation & $\begin{array}{l}\text { Implementation without technical/structural defects, integration and correct dimensioning } \\
\text { of insulation elements within the building, pre-settings of heating systems, etc. }\end{array}$ \\
\hline Energy poverty & Before renovation, one could not afford to keep the apartment adequately warm \\
\hline Energy consulting & $\begin{array}{l}\text { Communication of product information on building insulation, insulation materials and } \\
\text { technologies as well as the appropriate use of technology }\end{array}$ \\
\hline $\begin{array}{l}\text { Window of opportunity from } \\
\text { stock turnover }\end{array}$ & $\begin{array}{l}\text { Remaining technology lifetime and urgency of renewal of building elements such as heating, } \\
\text { windows, etc. }\end{array}$ \\
\hline Habits & Automatic maintenance of everyday routines \\
\hline Plumbers and construction companies & Responsible for planning, implementation of renovations; communicate product information \\
\hline Difficulty of applying for subsidies & $\begin{array}{l}\text { Necessary steps to obtain subsidies, number of involved bodies and actors up to the grant } \\
\text { approval (e.g., banks, municipal/state and federal authorities) }\end{array}$ \\
\hline Knowledge about the use of technology & Knowledge about proper heating and ventilation \\
\hline
\end{tabular}


Table 2 Scale definition of effect coefficients in the pathway maps

\begin{tabular}{ll}
\hline Numerical value & Definition \\
\hline 0 & No connection, changing one element does not change the other element. \\
0.25 & Small change, a change of one element causes a marginal change in the other element. \\
0.5 & Partial change, a change of one element causes a medium to large change in the other element. \\
0.75 & Equivalent change, a change of one element causes a change of equal size in the other element. \\
1 & Multiple change, changing one element causes a manifold change in the other element. \\
Positive coefficient & Positive causal direction, an increase of one element leads to increase of the other element. \\
Negative coefficient & Negative causal direction, an increase of one element leads to a decrease of the other element. \\
\hline
\end{tabular}

of influence by magnitude; they may be interpreted in relation to each other, but should not be mistaken as exact metric indicators. In the original research methods, the expert-based weights and the regression coefficients of the survey are scaled to capture up to equivalent change between elements, whereas the macroeconomic analysis also considers multiple change emerging from feedback effects between macroeconomic sectors. Capping multiple change to the value of 1 is necessary to give fair weight to all three methods; otherwise, the macroeconomic results would dominate the pathway map. Tables A.1 and A.2 (see Additional file 1) list the sources of the respective coefficients; where necessary, the three research methods are complemented by pertinent literature, cross-technology analogies, and expert assumptions. The coefficients are dimensionless and do not refer to a uniform monetary or physical unit. Forcing all map elements into a uniform metric such as Euro or $\mathrm{kg} \mathrm{CO}_{2}$ would distort their meaning and would undermine the core benefit of pathway mapping of integrating highly diverse, tangible as well as intangible drivers into a common framework. Yet, for reference, the scale may be interpreted similar to normalized regression coefficients or Cohen's effect sizes, such as when a change in one element by one standard deviation leads to a change in another element by a small or partial fraction of a standard deviation.

Integration creates the actual pathway map. The sequence of adoption, use (in terms of a direct and indirect rebound effect), and the cumulative effect resulting from use (economy-wide rebound effect) constitutes the core map structure. The elements are lined up in this structure in terms of their impacts and connected with directional arrows indicating direction and strength. The pathway map shows which elements act where and to what extent in the conflict between adoption and use, thus triggering or avoiding rebound effects. Single impacts are summed up to impact pathways, which either reinforce each other or cancel each other out. The pathway maps presented here focus on factors influencing both adoption and use; for simplification, the obvious direct influence of purchase/investment on macroeconomic elements is excluded.
Policy analysis employs the pathway map to identify levers for avoiding rebound. Selected policies change the level of individual map elements. This impulse propagates through the map via the relationships between the elements, depending on the sign and magnitude of the effect coefficients assigned to the directional arrows. The cumulative effect of an initial impulse is estimated by multiplying the effect coefficients along a particular pathway. Map elements with positive effect coefficients (green arrows in Fig. 1 and 2) on adoption as well as on avoidance of rebound are labeled convergent drivers, as strengthening these elements advances both policy goals of technology adoption and ecological use. Contrastingly, divergent drivers with negative effect coefficients (red arrows) undermine one policy goal at the expense of the other. The pathway map thus enables an analysis of which policies are best suited to counteract rebound effects holistically and to resolve the conflict between adoption and use.

In sensitivity analysis, the robustness of multiplicative effects is scrutinized by a one-at-a-time sensitivity analysis [54-56]. The most influential, i.e., biggest, parameter in each product term is varied while all other parameters are held constant in order to illustrate the bandwidth of effects. Since parameter distributions are not available, which precludes the common procedure of varying parameters by \pm 1 standard deviation, we opt for a plausible and reasonably likely parameter range of $\pm 15 \%$ as it is used in system models for policy analysis [57]. The resulting sensitivity range of each multiplicative effect is given in square brackets.

Applying pathway mapping comes with important caveats. The effect coefficients assigned during scaling are associated with uncertainties from combining different disciplinary approaches and only reflect the current Austrian context. In other countries, under other socio-political conditions, with other energy-efficient technologies, other effect coefficients would yield different results. Still, the focus here is to simulate the relative proportions of the different policy instruments in order to identify central levers. It is important to keep in mind that the purpose of pathway mapping lies in illustrating and exploring impact chains beyond disciplinary restrictions. Although it may appear as a 


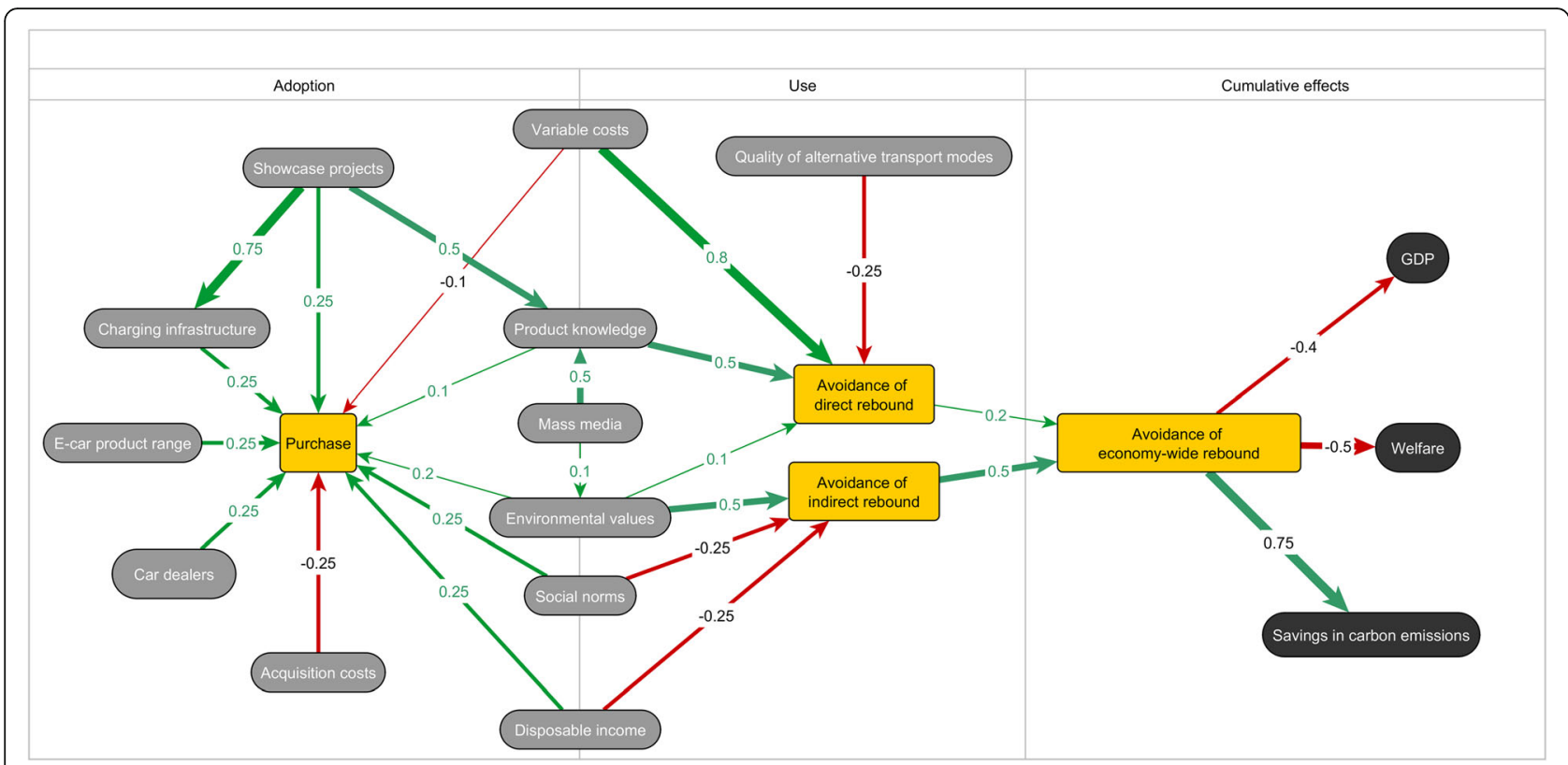

Fig. 1 E-car pathway map. Coefficients are compiled from three disciplinary approaches. Negative coefficients highlighted in red

system model, pathway mapping should not be misconceived as a numerical representation of a complex and dynamic system. We strongly advise against using the multiplicative effects derived in the policy simulation as estimates of the absolute impact of a certain policy. The multiplicative effects are useful for comparative analysis alone; accordingly, a sensitivity analysis with more elaborate parameter variation would be a meaningless pursuit that does not contribute relevant information [58]. Absolute projections, e.g., for picturing future energy systems, would require much more detail in the identification (e.g., specifying expenditures separately from energy intensity in the demand for other goods and services in indirect rebound), scaling (e.g., introducing "hard" metrics for the assessment of cost-effectiveness and carbon reductions in certain policies), and integration steps (e.g., adding reinforcing or regulating feedback loops between elements).

\section{Results}

Dynamics and interdependencies of the map elements

The e-car pathway map features several factors that promote the purchase of an e-car, as shown in the left

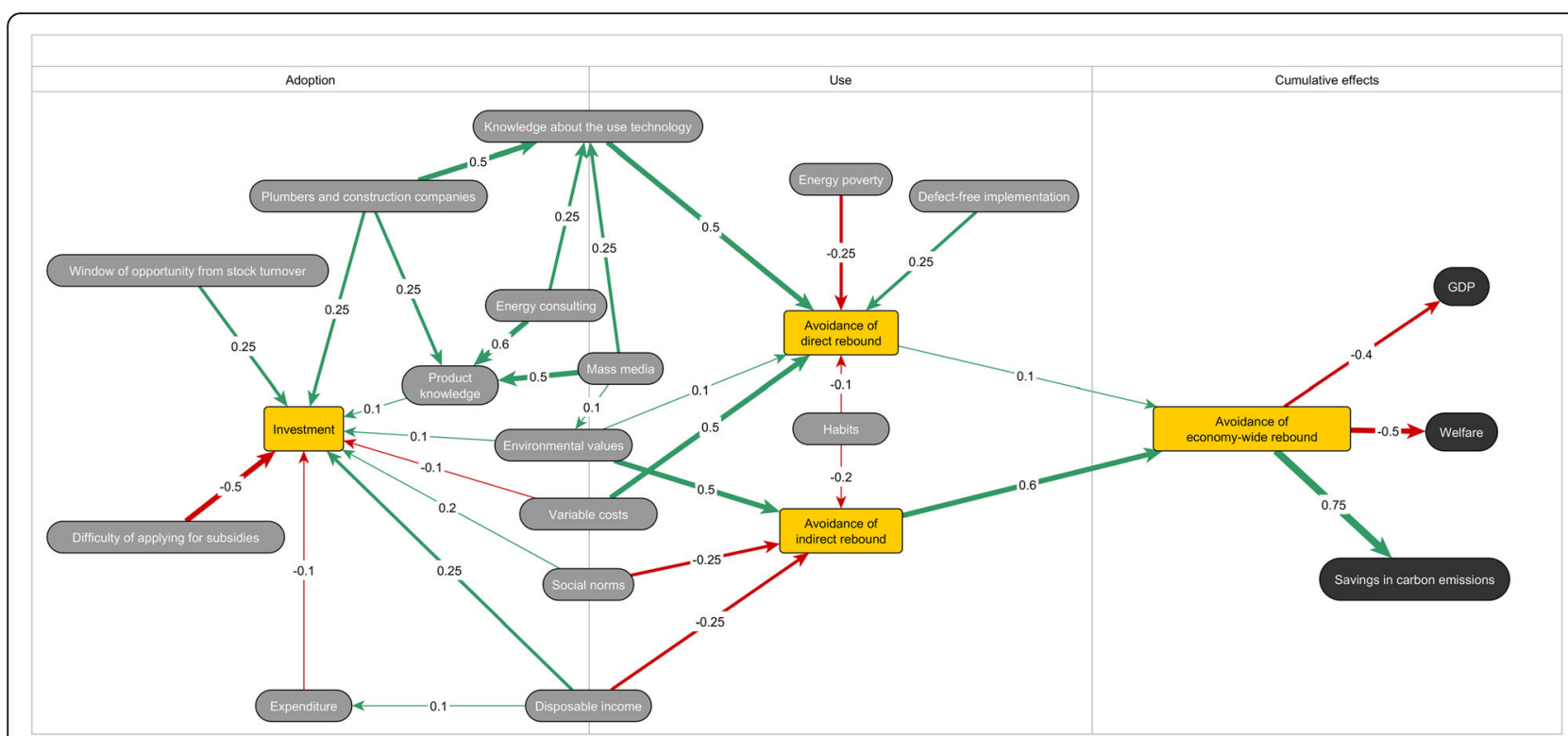

Fig. 2 Building renovation pathway map. Coefficients are compiled from three disciplinary approaches. Negative coefficients highlighted in red 
section of Fig. 1. Elements with a positive coefficient support e-car adoption, for example: high social norms, high disposable income, a well-developed charging infrastructure, and a wide product range of different e-cars. In addition to these psychological, socio-economic, and technical factors, car dealers and showcase projects as market players also promote e-car purchases. In contrast to these favorable elements, acquisition costs and variable costs act as limiting factors.

The middle section of the pathway map underscores divergent impacts on adoption versus use. On the one hand, the prospect of higher costs per kilometer, eventually caused by rising electricity costs or road pricing, makes the purchase of an e-car less likely (negative coefficient); on the other hand, higher variable costs reduce the frequency of use and thus help to prevent direct rebound. A comparison of the two coefficients shows that from an environmental policy point of view, the drawback of higher costs per kilometer slowing adoption $(-0.1)$ may be acceptable in order to benefit from a strong reduction of the direct rebound (0.8). Disposable income and social norms favor the purchase of an e-car, but exert the same influence on consumption in other areas, thus instigating indirect rebound.

The pathway map also contains elements with convergent effects. Product knowledge and environmental values promote acquisition and avoid direct and indirect rebound. Taken together, the divergent and convergent effects enacted by specific elements underline the counterproductive effects of policies that focus heavily on financial incentives or gains in social prestige. Informative or awareness-raising measures, on the other hand, steer both adoption and use in an environmentally desirable direction.

The building renovation pathway map contains more elements with more complex interrelations (Fig. 2) than the e-car case. Nevertheless, central impact patterns are similar: environmental values reconcile adoption and use, while disposable income, social norms, and variable heating costs increase the conflict between adoption and use. Important factors influencing the uptake of renovations are windows of opportunity from stock turnover and the difficulty of applying for public subsidies. The latter is by far the biggest obstacle in carrying out a renovation. Compared to the e-car pathway map, two additional factors counteract direct rebound: energy poverty and technical implementation.

The building renovation pathway map illustrates the role of intermediary actors. Mass media, plumbers and construction companies, and energy consultants have little direct influence on adoption or use, but act indirectly through other map elements such as product knowledge or knowledge about the use of technology. The latter has high potential to avoid direct rebound and is advanced by all these intermediary actors. These intermediary relationships indicate that effective policies should address a mix of elements rather than pinpoint only those elements directly connected to adoption or use.

Both pathway maps point to key actors who can resolve contradictory incentives for adoption and use. The more plumbers and construction companies are trusted and the more competence is attributed to them, the sooner a household decides to renovate a building. At the same time, plumbers and construction companies increase household knowledge about proper heating and ventilation, thus counteracting direct rebound. In the e-car pathway map, this balancing role is played by showcase projects: they create favorable conditions for the purchase of an e-car and at the same time contribute to environmentally friendly use through knowledge transfer. Policymakers are well advised to include such key actors in policy deployment.

In both pathway maps, the economy-wide rebound is primarily driven by indirect rebound. Reallocating savings from efficiency gains to other consumption domains has a much stronger rebound effect than the increase in direct use. A high economy-wide rebound reflects contradictory economic, social, and environmental objectives. Increased consumption leads to economic development, as the GDP grows, and subsequently, due to higher wages and more possibilities for consumption, welfare rises. However, increased consumption also means that energy and carbon savings turn out lower than originally expected. Because of economic interdependencies, this compensatory effect can go so far that the total energy and carbon savings are offset by increased consumption.

Both pathway maps show the same levers to avoid indirect (and by extension economy-wide) rebound: (i) high environmental values, which shift consumption mainly to non-energy-intensive sustainable products; (ii) weak social norms, since the gain in prestige from adopting an energy-efficient technology then serves less as a justification for increased consumption; and (iii) low disposable income, which reduces consumption or shifts expenditures to cheaper and less energy-intensive products. However, leveraging income for rebound prevention by introducing a flat-rate tax on efficiency gains is likely to come up against the limits of political feasibility and public acceptance.

\section{Simulating policy impacts using a pathway map}

Finally, we outline which policy measures are best suited to counteract rebound effects and to resolve the conflict between adoption and use. Thereby, we extend current rebound prevention pathways [7] with a comparative impact assessment of various policy measures. Note that the "units" of effects described below do not refer to monetary or physical scales, but to ordinal degrees of change (see also the scaling step in the "Method" section). 
Current policy strategies for the promotion of energyefficient technologies primarily rely on fiscal instruments designed to reduce variable costs. In Austria, for example, electricity for the operation of the vehicle is not subject to fuel tax; and in many large cities, e-cars do not pay for parking. In the e-car pathway map, a reduction of the variable costs per kilometer by one unit means that purchase increases by 0.1 units, but at the same time the direct rebound increases by 0.8 units (see Fig. 1, arrows originating from variable costs). The direct rebound continues in the map and leads to a reduction in carbon emission savings of 0.12 units $(0.8 * 0.2 * 0.75)$ $[0.10,0.14]$. A similar but less pronounced picture can be seen in the building renovation pathway map: lower energy taxes for certain heating energy sources (e.g., biomass, district heating) reduce the costs per comfortably heated square meter of living space. This results in an investment activity marginally higher by 0.1 units, but reduces carbon savings by 0.04 units $(0.5 * 0.1 * 0.75$, rounded) [0.03, 0.04].

Educational campaigns to increase environmental values and environmental literacy, on the other hand, promise significantly higher effects. Here too, the direct effect on adoption is small ( 0.2 for e-cars, 0.1 for renovation). However, since environmental values address both direct and indirect rebound, the effects on carbon savings stack up. In the renovation case, an increase in environmental values by 1 unit reduces carbon emissions by 0.23 units, mostly via the indirect rebound pathway $(0.5 * 0.6 * 0.75=0.225)$ and slightly via the direct rebound pathway $\left(0.1^{*} 0.1 * 0.75=0.0075\right)[0.20,0.27]$. With the ecar, environmental values have a 0.20 impact on carbon emissions $(0.1 * 0.2 * 0.75$ (direct) $+0.5 * 0.5 * 0.75$ (indirect)) $[0.17,0.25]$. Thus, promoting environmental values seems to be an effective intervention strategy. However, a far-reaching shift in values might only be achieved through protracted social change. Contrastingly, financial incentives are much easier and faster to implement.

Key actors may swiftly and effectively accelerate the market uptake of energy-efficient technologies. In the case of e-cars, expanding showcase projects by 1 unit will support the purchase of an e-car by a total of 0.49 units (direct influence: 0.25 ; via charging infrastructure: $0.75^{*} 0.25$; via product knowledge: $0.5 \% 0.1)$ [0.41, 0.56]. The impact of showcase projects on product knowledge propagates through the pathway map and contributes slightly to the reduction of carbon emissions $(0.04=0.5 * 0.5 * 0.2 * 0.75)$ $[0.04,0.04]$. Plumbers and construction companies, the renovation map's counterpart to showcase projects, have similar effects. These actors increase adoption by a total of 0.28 (direct influence: 0.25 ; via product knowledge: $0.25 * 0.1)[0.23,0.32]$ and lead to carbon emission savings of $0.02(0.5 * 0.5 * 0.1 * 0.75)$ [0.02, 0.02]. Thus, it seems advisable to involve those key actors in policy deployment since they offer double benefits: they increase adoption and additionally initiate (albeit small) carbon savings by imparting product knowledge.

\section{Discussion}

As mentioned above, these multiplicative effects only apply to the exemplary Austrian context in the year 2017. Integrating additional research methods in the selection and parameterization of map elements may yield more valid estimates. However, the multiplicative effects outlined here are mainly governed by the positive or negative sign of the directional relationships between map elements, i.e., their convergent or divergent effects. Even if some effect coefficients featured other magnitudes in other national contexts, the inherent conflict of, e.g., financial incentives pushing adoption as well as rebound would remain. The pathway maps are most sensitive to changes in the downstream effects of direct/ indirect rebound on economy-wide rebound, or of economy-wide rebound on carbon emissions (i.e. righthand sections of Figs. 1 and 2). The higher those downstream effect coefficients, the more severely upstream conflicts between adoption and use may undermine overall climate policy efforts.

While the pathways are simplified to a linear and static structure, reciprocal interrelations between map elements are included in the three research methods the maps are developed from. As examples, in fuzzy cognitive mapping, increasing private e-car purchases encourage car dealers to intensify their marketing efforts and to approach even more customers. The analysis of the household survey considers that social norms are internalized to personal environmental values through socialization processes. In the macroeconomic analysis, increased demand from indirect rebound triggers a redistribution of private consumption between economic sectors, which adds up to the observed economy-wide rebound.

Structural equation modeling (SEM) and agent-based modeling (ABM) could be alternatives to pathway mapping as they also depict a causal interrelational structure between model elements. However, they differ in crucial aspects from pathway mapping: Both SEM and ABM need a uniform unit of analysis that applies throughout the model. In SEM, these are typically private households [59]; in ABM, agents might be consumers, cars, buildings, or key actors like car dealers and plumbers. However, neither SEM nor ABM are well suited to simultaneously accommodate a range of qualitatively different elements (actors, individual attributes, technical or infrastructural aspects) as diverse as pathway mapping does. Both SEM and ABM rely on strict numerical, quantitative parameterization of factors and require large, mainly empirically based, datasets; to take full advantage of its capabilities, SEM furthermore requires 
operationalization of latent constructs by multiple indicators. In contrast to SEM and ABM, pathway mapping is also suited for less strict, semi-quantitative parameters, as they are commonly used in policy assessment. Nevertheless, SEM and ABM are useful to complement pathway mapping, as the present study does in analyzing the household survey with SEM and then integrating the SEM path coefficients with other effect coefficients in the scaling step.

\section{Conclusions}

The broad market introduction of energy-efficient technologies is widely considered a cornerstone in the lowcarbon transformation of modern societies. However, we argue that this policy strategy faces an inherent conflict between adoption and use, as policies for promoting market penetration often set the stage for ensuing rebound effects. The pathway mapping presented here integrates results from three complementary research methods and illustrates the dynamics between factors influencing adoption as well as use. Thereby, the pathway maps point to levers for resolving the conflict between adoption and use for the cases of e-cars and building renovations.

Market-oriented instruments such as tax exemptions for e-cars (as in Austria and Germany) or excluding ecars from urban toll systems (as in London and Stockholm) are at the heart of the conflict between adoption and use. These incentives weakly promote the acquisition of the energy-efficient technology, but also have the side-effect of advancing direct rebound. The overall impact of financial incentives on carbon savings is weak, since they apply only to specific technologies and neglect indirect rebound.

Instead, our analysis suggests not to underestimate the role of environmental values and key actors in policy design. Both factors accelerate market penetration and cushion indirect rebound. Media campaigns and social networks could convey environmental mindsets and make existing pro-environmental values salient. Plumbers and construction companies could be trained in product knowledge transfer. State programs could support the implementation of showcase projects and pilot regions.

Combined policies instead of stand-alone measures may also compensate for different measures becoming effective over different periods of time. Taxes and subsidies have a direct and short-term effect; training, campaigns, or media activities deploy in the medium term; a change in values or consumption practices develops over the course of up to one generation. The transformation to a low-carbon society will take several decades. Therefore, it seems sensible to systematically stagger short-, medium-, and long-term measures. To account for a temporal dimension, pathway maps would have to be extended, e.g., by including feedback or threshold effects between map elements or by allowing that over time causal directions may reverse, coefficients may shift in magnitude, or new elements may be added to the map.

Both pathway maps underline that indirect rebound, i.e., shifting savings from efficiency gains to other energyintensive consumption domains, by far outnumbers the increase in direct use. Product standards or an emission cap could counteract those indirect effects. Product standards already exist in several consumer domains (e.g., fuel standards for vehicles, energy efficiency labels for electronic devices). If universal emission standards were implemented, shifts in consumption would turn out less carbon intensive regardless of the particular domain the consumption is shifted to. Individual emission caps, such as an annual personal carbon budget, would steer consumers towards low-carbon products and services. Whereas product standards are a well-established policy instrument, it is difficult however to imagine how personal carbon budgets could be administered and controlled in practice. For investigating the dynamics of product standards and personal carbon budgets, the system boundaries of both pathway maps would have to be extended to cater for other consumption domains besides transport and housing, production-side economics, or factors beyond the scope of household decision-making. However, the introduction of additional elements would make the maps more complex and harder to interpret.

Developing pathway maps which apply to a wide range of energy-efficient technologies remains a desideratum for future studies. E-cars and building renovation, or other examples such as private photovoltaics panels or LED light bulbs, represent mature technologies already established on the market. Here, substantial scientific and practical knowledge has accumulated which allows selecting map elements and parameterizing effect coefficients. By replication in other case studies, the basic map structure, elements, and effect coefficients could be validated. However, key actors such as showcase projects or plumbers and construction companies may need to be identified specifically for each technology. Still, a generalized pathway map could facilitate prospective policy design for emergent technological innovations which currently cater to market niches, but may soon turn into full-fledged products or services that also underlie the risk of conflicts between adoption and use.

\section{Additional file}

Additional file 1: Online appendix. (DOCX $51 \mathrm{~kb}$ )

Abbreviations

ABM: Agent-based modeling; CGE: Computable general equilibrium;

GDP: Gross domestic product; SEM: Structural equation modeling 


\section{Acknowledgements}

Sincere thanks go to three anonymous reviewers for valuable comments.

\section{Authors' contributions}

SS conducted the household survey. VK conducted the CGE modeling. CF conducted the fuzzy cognitive mapping. All authors contributed to, read, and approved the final manuscript.

\section{Funding}

This research was funded by the Climate and Energy Fund and carried out within the Austrian Climate Research Program (project number: B464789). Furthermore, this research was supported by the Mobility of the Future program of the Austrian Federal Ministry for Transport, Innovation and Technology (project number: 860929).

\section{Availability of data and materials}

Datasets analyzed during this study were either obtained from third parties or were generated by surveying individuals. Data are available from the corresponding author upon reasonable request; if necessary, the corresponding author is committed to assist in negotiating licenses with third parties.

\section{Ethics approval and consent to participate}

The study was conducted according to JOANNEUM RESEARCH's ethics guidelines.

\section{Consent for publication}

Not applicable, since the study reports only aggregated data.

\section{Competing interests}

The authors declare that they have no competing interests.

Received: 27 August 2018 Accepted: 24 June 2019

\section{Published online: 02 July 2019}

\section{References}

1. EC European Commission (2012) Energy roadmap 2050. https://ec.europa. eu/energy/sites/ener/files/documents/2012_energy_roadmap_2050_en_0. pdf. Accessed 28 June 2019

2. IEA International Energy Agency (2017) Global EV Outlook 2017. OECD/IEA, Paris

3. IEA International Energy Agency (2014) Capturing the multiple benefits of energy efficiency. OECD/IEA, Paris

4. Holtsmark B, Skonhoft A (2014) The Norwegian support and subsidy policy of electric cars. Should it be adopted by other countries? Environ Sci Policy 42:160-168. https://doi.org/10.1016/j.envsci.2014.06.006

5. BMNT Federal Ministry of Sustainability and Tourism, BMVIT Federal Ministry of Transport Innovation and Technology (2018) \#mission 2030 Austrian climate and energy strategy. https://mission2030.info/wp-content/uploads/ 2018/10/Klima-Energiestrategie_en.pdf. Accessed 28 June 2019.

6. de la Rue du Can S, MA MN, Leventis G (2015) Rebound effects in the context of developing country efficiency programs. research report. Lawrence Berkeley National Laboratory, Berkeley. https://doi.org/10.2172/ 1377400

7. Font Vivanco D, Kemp R, van der Voet E (2016) How to deal with the rebound effect? A policy-oriented approach. Energ Policy 94:114-125. https://doi.org/10.1016/.enpol.2016.03.054

8. Graham-Rowe E, Gardner B, Abraham C, Skippon S, Dittmar H, Hutchins R, Stannard J (2012) Mainstream consumers driving plug-in battery-electric and plug-in hybrid electric cars: a qualitative analysis of responses and evaluations. Trans Res A 46:140-153. https://doi.org/10.1016/j.tra.2011.09.008

9. Sorrell S (2007) The rebound effect: an assessment of the evidence for economy-wide energy savings from improved energy efficiency. Research report, UK Energy Research Center, London. file:///C:/Users/kuv/Downloads/ The\%20Rebound\%20Effect_

\%20An\%20Assessment $\% 20$ of\%20the\%20Evidence\%20for\%20Economywide $\% 20$ Energy $\% 20$ Savings $\% 20$ from $\% 20$ Improved\%20Energy $\% 20$ Efficiency. pdf. Accessed 26 Jul 2018.

10. Santarius T (2014) Der Rebound-Effekt: ein blinder Fleck der sozialökologischen Gesellschaftstransformation. English translation: Rebound effects: blind spots in the socio-ecological transition of industrial societies. GAIA - Ecol Perspect Sci Soc 23(2):109-117. https://doi.org/10. 14512/gaia.23.2.8
11. Thomas B, Azevedo IML (2013) Estimating direct and indirect rebound effects for U.S. households with input-output analysis Part 1: theoretical framework. Ecol Econ 86(0):199-210. doi:https://doi.org/10.1016/j.ecolecon. 2012.12.003.

12. Azevedo IML (2014) Consumer end-use energy efficiency and rebound effects. Annu Rev Env Resour 39:393-418. https://doi.org/10.1146/annurevenviron-021913-153558

13. Allan G, Hanley N, McGregor P, Swales K, Turner K (2007) The impact of increased efficiency in the industrial use of energy: a computable general equilibrium analysis for the United Kingdom. Energ Econ 29(4):779-798. https://doi.org/10.1016/j.eneco.2006.12.006

14. Turner K (2013) Rebound effects from increased energy efficiency: a time to pause and reflect. Energ J 34(4):25-42. https://doi.org/10.5547/01956574.34.4.2

15. Gillingham K, Rapson D, Wagner G (2016) The rebound effect and energy efficiency policy. Rev Environ Econ Policy 10(1):68-88. https://doi.org/10. 1093/reep/rev017

16. Friedrichsmeier T, Matthies $E$ (2015) Rebound effects in energy efficiency an inefficient debate? GAIA - Ecol Perspect Sci Soc 24(2):80-84. https://doi. org/10.14512/gaia.24.2.3

17. Turner K (2009) Negative rebound and disinvestment effects in response to an improvement in energy efficiency in the UK economy. Energ Econ 31(5): 648-666. https://doi.org/10.1016/j.eneco.2009.01.008

18. Guerra A, Sancho F (2010) Rethinking economy-wide rebound measures: an unbiased proposal. Energ Policy 38(11):6684-6694. https://doi.org/10.1016/j. enpol.2010.06.038

19. Geels FW (2004) From sectoral systems of innovation to socio-technical systems: insights about dynamics and change from sociology and institutional theory. Res Policy 33:897-920. https://doi.org/10.1016/j.respol. 2004.01.015

20. Markard J, Hekkert MP, Jacobsson S (2015) The technological innovation systems framework: response to six criticisms. Environ Innov Soc Transitions 16:76-86. https://doi.org/10.1016/j.eist.2015.07.006

21. Boulanger P-M, Couder J, Marenne $Y$, Nemoz S, Vanhaverbeke J, Verbruggen A, Wallenborn G (2013) Household energy consumption and rebound effect. Belgian Science Policy, Brussels, p 3361. https://doi. org/10.13140/RG.2.1.3515

22. Steg L, Perlaviciute G, van der Werff E (2015) Understanding the human dimensions of a sustainable energy transition. Front Psychol 6:805. https:// doi.org/10.3389/fpsyg.2015.00805

23. Peters A, Sonnberger M, Dütschke E, Deuschle J (2012) Theoretical perspective on rebound effects from a social science point of view: working paper to prepare empirical psychological and sociological studies in the REBOUND project. Working Paper Sustainability and Innovation No. S2/2012. Fraunhofer ISI, Karlsruhe. https://www.isi.fraunhofer.de/content/dam/isi/ dokumente/sustainability-innovation/2012/WP02-2012_Rebound_ psychological_sociological_background.pdf. Accessed 28 June 2019.

24. Santarius T, Soland M (2018) How technological efficiency improvements change consumer preferences: towards a psychological theory of rebound effects. Ecol Econ 146:414-424. https://doi.org/10. 1016/j.ecolecon.2017.12.009

25. Biermayr P, Schriefl E, Baumann B, Sturm A (2005) Maßnahmen zur Minimierung von Reboundeffekten bei der Sanierung von Wohngebäuden. English Translation: Measures for minimizing rebound effects in building redevelopment. In Federal Ministry for Transport, Innovation and Technology (eds) Online Platform Sustainable Development 6/2005. https:// nachhaltigwirtschaften.at/de/hdz/projekte/massnahmen-zur-minimierungvon-rebound-effekten-bei-der-sanierung-von-wohngebaeuden-maresi.php. Accessed 28 June 2019.

26. Lopez-Fernandez O, Molina-Azorin JF (2011) The use of mixed methods research in the field of behavioural sciences. Qual Quant 45(6):1459-1472. https://doi.org/10.1007/s11135-011-9543-9

27. Tapio P, Paloniemi R, Varho V, Vinnari M (2011) The unholy marriage? Integrating qualitative and quantitative information in Delphi processes. Technol Forecast Soc 78:1616-1628. https://doi.org/10.1016/j.techfore. 2011.03.016

28. Robertson E, O'Grady Á, Barton J, Galloway S, Emmanuel-Yusuf D, Leach M, Hammond G, Thomson M, Foxon T (2017) Reconciling qualitative storylines and quantitative descriptions: an iterative approach. Technol Forecast Soc 118:293-306. https://doi.org/10.1016/j.techfore.2017.02.030

29. Samarasinghe S, Strickert GEH (2013) Mixed-method integration and advances in fuzzy cognitive maps for computational policy simulations for 
natural hazard mitigation. Environ Modell Softw 39:188-200. https://doi.org/ 10.1016/j.envsoft.2012.06.008

30. Robertson S (2016) A longitudinal quantitative-qualitative systems approach to the study of transitions toward a low carbon society. J Clean Prod 128: 221-233. https://doi.org/10.1016/j.jclepro.2015.04.074

31. Pye S, Li FGN, Petersen A, Broad O, Mcdowall W, Price J, Usher W (2018) Assessing qualitative and quantitative dimensions of uncertainty in energy modelling for policy support in the United Kingdom. Energ Res Soc Sci 46: 332-344. https://doi.org/10.1016/j.erss.2018.07.028

32. Zou PXW, Xu X, Sanjayan J, Wang J (2018) A mixed methods design for building occupants' energy behavior research. Energ Buildings 166:239-249. https://doi.org/10.1016/j.enbuild.2018.01.068

33. Brown G, Strickland-Munro J, Kobryn HT, Moore SA (2017) Mixed methods participatory GIS: an evaluation of the validity of qualitative and quantitative mapping methods. Appl Geogr 79:153-166. https://doi.org/10.1016/j. apgeog.2016.12.015

34. Freeman R, Yearworth M, Cherreault J-Y (2014) Review of literature on systems thinking and system dynamics for policy making. Research report. Department for Environment, Food and Rural Affairs, London. https://doi. org/10.13140/RG.2.2.14203.00808. Accessed 28 June 2019

35. Olazabal M, Pascual U (2016) Use of fuzzy cognitive maps to study urban resilience and transformation. Environ Innov Soc Transit 18:18-40. https:// doi.org/10.1016/j.eist.2015.06.006

36. Isaac ME, Dawoe E, Sieciechowicz K (2009) Assessing local knowledge use in agroforestry management with cognitive maps. Environ Manag 43:13211329. https://doi.org/10.1007/s00267-008-9201-8

37. Papageorgiou El, Markinos A, Gemptos T (2009) Application of fuzzy cognitive maps for cotton yield management in precision farming. Expert Syst Appl 36:12399-12413. https://doi.org/10.1016/j.eswa.2009.04.046

38. Kafetzis A, McRoberts N, Mourantiadou I (2010) Using fuzzy cognitive maps to support the analysis of stakeholders' views of water resource use and water quality policy. In: Glykas M (ed) Fuzzy cognitive maps. Studies in fuzziness and soft computing, vol 247. Springer, Heidelberg, pp 383-402

39. Rajaram T, Das A (2010) Modeling of interactions among sustainability components of an agro-ecosystem using local knowledge through cognitive mapping and fuzzy inference system. Expert Syst Appl 37:17341744. https://doi.org/10.1016/j.eswa.2009.07.035

40. ̈Zzesmi U, Özesmi SL (2004) Ecological models based on people's knowledge: a multi-step fuzzy cognitive mapping approach. Ecol Model 176:43-64. https://doi.org/10.1016/j.ecolmodel.2003.10.027

41. Papageorgiou El, Kontogianni A (2012) Using fuzzy cognitive mapping in environmental decision making and management: a methodological primer and an application. In: Silvern SE, Young SS (eds) International perspectives on global environmental change. IntechOpen. https://doi. org/10.5772/29375

42. Fruhmann C, Türk A, Kulmer V, Seebauer S (2017) System complexity as key determinant in achieving efficacious policy transposition and implementation. In: Ashiabor H, Kreiser L, Mehling M, Milne J, Weishaar S (eds) The green market transition: carbon taxes, energy subsidies and smart instrument mixes. Critical issues in environmental taxation, vol 19. Edward Elgar Publishing, Cheltenham, pp 193-208

43. Byrne BM (2010) Structural equation modeling with AMOS: basic concepts, applications and programming, 2nd ed. Routledge, New York/London.

44. Venkatesh V, Morris MG, Davis GB, Davis FD (2003) User acceptance of information technology: toward a unified view. MIS Quart 27(3):425-478. https://doi.org/10.2307/30036540

45. Steg L, Nordlund A (2013) Models to explain environmental behavior. In: de Groot JIM, Steg L, van den Berg AE (eds) Environmental psychology: an introduction. BPS Blackwell, Chichester.

46. Seebauer S (2018) The psychology of rebound effects: explaining energy efficiency rebound behaviours with electric vehicles and building insulation in Austria. Energ Res Soc Sci 46:311-320. https://doi. org/10.1016/j.erss.2018.08.006

47. Lecca P, McGregor PG, Swales JK, Turner K (2014) The added value from a general equilibrium analysis of increased efficiency in household energy use. Ecol Econ 100:51-62. https://doi.org/10.1016/j.ecolecon.2014.01.008

48. Broberg T, Berg C, Samakovlis E (2015) The economy-wide rebound effect from improved energy efficiency in Swedish industries: a general equilibrium analysis. Energ Policy 83:26-37. https://doi.org/10.1016/j.enpol. 2015.03.026
49. Kulmer V, Seebauer S (2019) How robust are estimates of the rebound effect of energy efficiency improvements? A sensitivity analysis of consumer heterogeneity and elasticities. Energ Policy 132:1-14. https://doi.org/10. 1016/j.enpol.2019.05.001

50. Walker W, van Daalen CE (2013) System models for policy analysis. In: Thissen WAH, Walker WE (eds) Public policy analysis: new developments. International series in operations research \& management science, vol 179. Springer, Boston, pp 157-184

51. Bortz J, Döring N (2006) Forschungsmethoden und Evaluation. English Translation: Research methods and evaluation. Springer, Berlin

52. Strauss A, Corbin J (1998) Basics of qualitative research: techniques and procedures for developing grounded theory. Sage, Thousand Oaks CA

53. IPCC (2008) Appendix A to the Principles Governing IPCC Work. Procedures for the preparation, review, acceptance, adoption, approval and publication of IPCC reports. https://www.ipcc.ch/documentation/procedures/. Accessed 27 Feb 2019.

54. O'Neill R, Gardner R, Mankin J (1980) Analysis of parameter error in a nonlinear model. Ecol Mod 8:297-311

55. Hamby D (1994) A review of techniques for parameter sensitivity analysis of environmental models. Env Mon Ass 32(2):135-154

56. Saltelli A, Tarantola S, Campolongo F, Ratto M (2004) Sensitivity analysis in practice. A guide to assessing scientific models. John Wiley \& Sons, West Sussex

57. Caulkins J, Rydell C, Schwabe W, Chiesa J (1997) Mandatory Minimum Drug Sentences: Throwing Away the Key or the Taxpayers' Money? RAND Corporation, Santa Monica

58. Pilkey O, Pilkey-Jarvis L (2009) Useless arithmetic: why environmental scientists can't predict the future. Columbia University Press, New York

59. Golob T (2003) Structural equation modeling for travel behavior research. Trans Res B 37:1-25. https://doi.org/10.1016/S0191-2615(01)00046-7

\section{Publisher's Note}

Springer Nature remains neutral with regard to jurisdictional claims in published maps and institutional affiliations.
Ready to submit your research? Choose BMC and benefit from:
- fast, convenient online submission
- thorough peer review by experienced researchers in your field
- rapid publication on acceptance
- support for research data, including large and complex data types
- gold Open Access which fosters wider collaboration and increased citations
- maximum visibility for your research: over $100 \mathrm{M}$ website views per year
At BMC, research is always in progress.
Learn more biomedcentral.com/submissions 